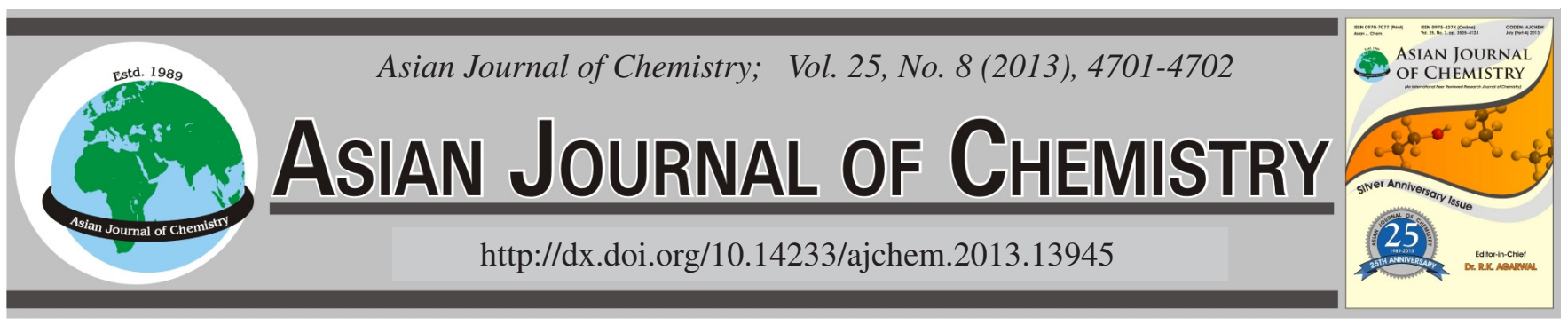

NOTE

\title{
Analysis of the Essential Oil from Seed of Heracleum moellendorffii Hance Cultivated in Northeast China
}

\author{
Wei Li* ${ }^{*}$ Linlin Chen, Chun Wu and Jiaying Xin
}

Key Laboratory of Food Science and Engineering, College of Food Engineering, Harbin University of Commerce, Harbin, P.R. China

*Corresponding author: Tel/Fax: +86 451 84844281; E-mail: liw@ hrbcu.edu.cn

(Received: 23 April 2012;

Accepted: 26 February 2013)

AJC-13048

\begin{abstract}
Essential oil from seed of Heracleum moellendorffii Hance was obtained by hydrodistillation and analyzed by gas chromatography and gas chromatography mass spectrometry. In total, 69 components were detected, 41 components $(98.60 \%)$ were identified, among of which the major components were octyl acetate $(63.80 \%)$, octyl butyrate $(12.23 \%)$ and $n$-octanol $(11.51 \%)$.

Key Words: Umbelliferae, Heracleum moellendorffii Hance, Essential oil, Octyl acetate.
\end{abstract}

Heracleum L. belongs to subtribe tordyliinae of tribe Peucedaneae, subfamily Apioideae Apiaceae. It comprises 70 species mainly distributed in temperate areas of Asia and Europe. Caueasus mountains and Hengduan mountains are the two distribution centre of Heracleum in the world ${ }^{1}$. There are 29 species together with 4 varieties in China $^{2}$.

Heracleum moellendorffii Hance is one specie of genus Heracleum. It is an herbaceous perennial plant that grows in the hurst brim and valley ${ }^{3}$. The tender leaf of plant has been served as edible delicious vegetable by people in Northeast of China, component of the root are coumarins that possess pharmic activity, it has been used for the treatment of proliferative arthritis, psoriasis and arrhythmia etc. ${ }^{4-7}$. The main component of essential oils composition from flowers of plants are octyl acetate . $^{8}$

Up to now, study on Heracleum moellendorffii Hance are still scanty. Here we reported the chemical composition of the essential oil from the seed of Heracleum moellendorffii Hance.

The seed of Heracleum moellendorffii Hance was cultivated in Northeast of China in 2007 and purchased from Taoshan Medicinal Materials Plantation in Tieli city, Heilongjiang province, China, in 2008. The seed was stored in cloth bag.

Extraction of essential oil: Essential oil from crushed seed was isolated in a Clevenger's apparatus by hydrodistillation for $4 \mathrm{~h}$ when there was no increase in tube collected. The raw product was transferred by pipette into $4 \mathrm{~mL}$ sample flask and dried over anhydrous sodium sulfate. The essential oil was obtained by filtrate and stored at $4{ }^{\circ} \mathrm{C}$ before analysis. The oil yield was $6.39 \%(\mathrm{v} / \mathrm{w})$.

Gas chromatography (GC): Gas chromatography analysis were performed on a Agilent GC6890 gas chromatograph (FID), fitted with a $30 \mathrm{~m} \times 0.25 \mathrm{~mm} \times 0.25 \mu \mathrm{m}$ HP-5MS capillary column, using nitrogen as the carrier gas. The inlet temperature was $260^{\circ} \mathrm{C}$, the split was $50: 1$, the volume of injection was $0.2 \mu \mathrm{L}$. The oven tempe-rature was programmed from $60^{\circ} \mathrm{C}$ (after $1 \mathrm{~min}$ ) to $240^{\circ} \mathrm{C}$ at $6^{\circ} \mathrm{C} / \mathrm{min}$ and the end temperature was held for $10 \mathrm{~min}$. Peaks area percents were used for obtaining quantitative data.

Gas chromatography mass spectrometry: The GC-MS analysis of the oil was carried out on an Agilent HP-6890N gas chromatograph equipped $5973 \mathrm{~N}$ mass spectrometry detector and HP-5MS capillary column $(30 \mathrm{~m} \times 0.25 \mathrm{~mm}$, $0.25 \mu \mathrm{m}$ ) in the electron impact mode(Ionization energy: 70 $\mathrm{eV}$ ) operating under the same conditions as described above. The retention indices were calculated relative to C6-C24 $n$-alkanes. The data aquired were analyzed by AMDIS software, The constituents of the oils were identified by matching with the NIST2005.L and Wiley275.L libraries, also by comparing their Kovat's retention indices with reference libraries ${ }^{9}$.

The volatile constituents identified in the oil of Heracleum moellendorffii Hance are listed in Table-1 in order of their elution from the HP-5MS column. Hydrodistillation of the seed of Heracleum moellendorffii Hance afforded colourless oil with srong pungent odor, but aroma was smelt by a little, yield $6.39 \%$ (v/w), 69 components were detected, 41 components $(98.60 \%)$ were identified. Among of which the content 


\begin{tabular}{|c|c|c|}
\hline \multicolumn{3}{|c|}{$\begin{array}{c}\text { TABLE-1 } \\
\text { COMPONENTS IDENTIFIED IN THE OIL FROM } \\
\text { SEED OF Heracleum moellendorffii Hance }\end{array}$} \\
\hline Compounds & $\mathrm{RI}^{\mathrm{a}}$ & $\%^{\mathrm{b}}$ \\
\hline Ethanol & 543 & 0.01 \\
\hline 3-Buten-2-ol, 2-methyl- & 611 & 0.02 \\
\hline 2-Buten-1-ol, 3-methyl- & 773 & 0.03 \\
\hline$n$-Hexanal & 802 & 0.01 \\
\hline 1-Hexanol & 865 & 0.15 \\
\hline Octanal & 997 & 0.50 \\
\hline Acetic acid, hexyl ester & 1007 & 0.10 \\
\hline Butyl 2-methylbutanoate & 1043 & 0.02 \\
\hline 1-Butyl isovalerate & 1042 & 0.03 \\
\hline Butanoic acid, 2-methylbutyl ester & 1056 & 0.04 \\
\hline 3-Octen-1-ol & 1060 & 0.68 \\
\hline 1-Octanol & 1070 & 11.51 \\
\hline$\alpha$-Linalool & 1102 & 0.02 \\
\hline Butanoic acid, 2-methyl-, 2-methylbutyl ester & 1105 & 0.08 \\
\hline Butanoic acid, 3-methyl-, pentyl ester & 1109 & 0.03 \\
\hline Acetic acid, heptyl ester & 1113 & 0.03 \\
\hline Propanoic acid, 2-methyl-, hexyl ester & 1149 & 0.08 \\
\hline 3-Methyl-2-butenoic acid, 2-pentyl ester & 1186 & 0.03 \\
\hline Butanoic acid, hexyl ester & 1193 & 2.18 \\
\hline 3-Octen-1-ol, acetate & 1200 & 2.83 \\
\hline Decanal & 1207 & 0.26 \\
\hline Acetic acid, octyl ester & 1217 & 63.80 \\
\hline 3-Octen-1-ol, acetate & 1226 & 0.11 \\
\hline Butanoic acid, 2-methyl-, hexyl ester & 1238 & 0.13 \\
\hline Butanoic acid, 3-methyl-, hexyl ester & 1243 & 0.13 \\
\hline (Z)-4-Decen-1-ol & 1259 & 0.04 \\
\hline 1-Decanol & 1273 & 0.07 \\
\hline Propanoic acid, octyl ester & 1303 & 0.04 \\
\hline 2-Butenoic acid, 3-methyl-, hexyl ester & 1322 & 0.02 \\
\hline Propanoic acid, 2-methyl-, octyl ester & 1346 & 0.21 \\
\hline Butanoic acid, 1-ethenylhexyl ester & 1378 & 0.74 \\
\hline Octyl butyrate & 1440 & 12.23 \\
\hline 5-Decen-1-ol, acetate, (E)- & 1398 & 0.14 \\
\hline Z-7-Decen-1-yl acetate & 1402 & 0.19 \\
\hline Acetic acid, decyl ester & 1410 & 0.58 \\
\hline Butanoic acid, 2-methyl-, octyl ester & 1435 & 0.27 \\
\hline Pentanoic acid, octyl ester & 1440 & 0.18 \\
\hline 2(3H)-Furanone, 5-hexyldihydro- & 1472 & 0.08 \\
\hline 3-Methyl-2-butenoic acid, octyl ester & 1522 & 0.10 \\
\hline Hexanoic acid, octyl ester & 1584 & 0.80 \\
\hline 5-Dodecen-1-ol, acetate, (Z)- & 1589 & 0.10 \\
\hline Esters & & 85.21 \\
\hline Alcohols & & 12.62 \\
\hline Aldehydes & & 0.77 \\
\hline Total & & 98.60 \\
\hline
\end{tabular}

according sort were listed as follow esters (85.21\%), alcohols $(12.62 \%)$, aldehydes $(0.77 \%)$. Octyl acetate $(63.80 \%)$ was the major constituent in the oil, followed by 1-octanol (11.51\%) and octyl butyrate $(12.23 \%)$. Esters dominated in constituents of oil, octyl acetate is reported as main component in most species of Heracleum L. ${ }^{10-12}$. It was obvious different between the constituent of seed and flower or leaf that no terpenes were determined in oil of the seed ${ }^{8}$. The seed could be considered as a material source of natural octyl acetate and a sort of spice for its aroma.

\section{ACKNOWLEDGEMENTS}

The authors thank the Aid Program for Science and Technology Innovative Research Team in Higher Educational Instituions of Heilongjiang Province (2010td04), the Heilongjiang Provincial Funds for Distinguished Young Scientists (JC201106) and the Heilongjiang Province Natural Science Fund Project (B201001).

\section{REFERENCES}

1. S. Ren-Ye and S. Meng-Lan, Flour of China, Science Press, China, Vol 55(3), pp. 16-78, 184-212 (1992).

2. F.D. Pu, X.J. He, P.L. Wang and Y.P. Wang, Acta Phytotaxon. Sin., 31, 368 (1993).

3. Liu shen-e, Plant Keys of Northeast. Science Press, China, p. 473 (1959).

4. J.S. Eun, B.H. Choi, J.A. Park, G.I. Lee, T.Y. Lee, D.K. Kim, Y.H. Jung, D.J. Yoo and Y.G. Kwak, Arch. Pharm. Res., 28, 269 (2005).

5. Y.-S. Kwon, H.-Y. Cho, C.-M. Kim, et al., Yakhak Hoeji, 44, 521 (2000).

6. Y. Nakano, H. Matsunaga, T. Saita, M. Mori, M. Katano and H. Okabe, Biol. Pharm. Bull., 21, 257 (1998).

7. H.Q. Zhang, Zhong Yao Tong Bao, 6, 27 (1981).

8. K.G. Tkachenko, L.M. Pikrovsky and A.V. Tkachev, Communication 3. Essential oils of flowers and fruit, Rastitel'nye Resursy, 37, 69 (2001).

9. R.P. Adams, Identification of Essential Oil Components by Gas Chromatography/Quadrupole Mass Spectroscopy, Allured Publ. Corp., Carol Stream, IL, edn. 4 (2007).

10. K.G. Tkachenko, J. Essent. Oil Res., 6, 535 (1994).

11. F. Tosun, K.C. Akyuez and K. Erol, Food Chem., 107, 990 (2008).

12. A.J. John and V.P. Karunakaran, J. Essent. Oil Res., 19, 358 (2008). 